\title{
Remediação de solos tratados com lodo rico em zinco
}

\author{
Aline A. Mesquita ${ }^{1}$, Nelson M. B. Amaral Sobrinho ${ }^{1}$, Clarice de Oliveira ${ }^{1}$, Nelson Mazur ${ }^{1} \&$ Fabiana S. dos Santos ${ }^{1}$
}

\begin{abstract}
RESUMO
Esta pesquisa teve por objetivos: estudar as alterações na distribuição de Zn nas diferentes frações químicas de solos tratados com lodo de esgoto, provocadas pela aplicação de carbonatos, óxidos e fosfatos para determinar a eficiência desses produtos na contenção desse elemento, e avaliar a redução de solubilidade através do uso de planta hiperacumuladora. Utilizou-se lodo de esgoto de indústria aplicado em amostras da camada superficial de um Latossolo VermelhoAmarelo (LVA) e de um Argissolo Vermelho-Amarelo (PVA). A adição de $\mathrm{CaCO}_{3}$ provocou imobilização química do $\mathrm{Zn}$ por sua associação às frações químicas mais estáveis. $\mathrm{O} \mathrm{FeCl}$ + EDTA causou dissolução de compostos de $\mathrm{Zn}$ e dessorção desses elementos complexados por grupos funcionais de superfície. $\mathrm{O} \mathrm{KH}_{2} \mathrm{PO}_{4}$ não alterou a distribuição de $\mathrm{Zn}$ nas diferentes formas químicas nos solos. O Zn concentrou-se nas raízes, limitando a passagem desses elementos para a parte aérea. Encontrou-se, nos tratamentos com o $\mathrm{CaCO}_{3}$, menor concentração de $\mathrm{Zn}$ na raiz e parte aérea. A adição de $\mathrm{FeCl}_{3}+$ EDTA promoveu aumento da concentração de $\mathrm{Zn}$ nesses órgãos da planta.
\end{abstract}

Palavras-chave: metal pesado, Oryza sativa, contaminação do solo

\section{Reclamation of soils treated with sewage sledge rich in $\mathrm{Zn}$}

\begin{abstract}
This research had as objectives: to study the alterations in the distribution of $\mathrm{Zn}$ in different chemical carbonates fractions of soil treated with sewage sludge, caused by the application of carbonates, oxides and phosphates to determine the efficiency of these products in the contention of this element; and to evaluate the solubility reduction through the use of hyper accumulator plant. Industrial sewage sludge was applied in samples of surface layer of a Yellow Red Latossol and Yellow Red Argissol. The addition of $\mathrm{CaCO}_{3}$ caused chemical immobilization of $\mathrm{Zn}$ due to association of these elements with more stable chemical fractions. The $\mathrm{FeCl}_{3}+\mathrm{EDTA}$ caused dissolution of $\mathrm{Zn}$ compounds and dessorption of these elements quelated by surface functional groups. The $\mathrm{KH}_{2} \mathrm{PO}_{4}$ did not alter the distribution of $\mathrm{Zn}$ in the different chemical forms in the soils. The $\mathrm{Zn}$ concentrated, mainly in the roots, which behaved as a natural filter, limiting the flux of these elements to the aerial part. In both soils, $\mathrm{CaCO}_{3}$ caused the smallest concentration of $\mathrm{Zn}$ in the root and aerial part. The addition of $\mathrm{FeCl}_{3}+\mathrm{EDTA}$ promoted the increase of $\mathrm{Zn}$ levels in the plant.
\end{abstract}

Key words: heavy metals, Oryza sativa, soil contamination 


\section{INTRODUÇÃO}

As previsões de aumento populacional, associadas à crescente concentração urbana mundial, determinaram a necessidade imediata de definições tecnológicas e de ações políticas para solucionar o grave problema da destinação final do lodo de esgoto. Esta preocupação tem gerado um estímulo mundial para o desenvolvimento de práticas de minimização da produção de resíduos urbanos e priorização da reciclagem como opção de destino final.

Uma alternativa considerada bastante viável para a destinação do lodo de esgoto tem sido a reciclagem agrícola (Andreoli \& Perogini, 1999). Neste caso, tem-se o grande benefício de transformar um resíduo urbano em um insumo agrícola que fornece matéria orgânica e nutrientes ao solo, trazendo vantagens indiretas ao homem e ao meio ambiente. Algumas das vantagens seriam a redução dos efeitos adversos à saúde humana causado pela incineração e a diminuição da dependência de fertilizantes.

Apesar dos efeitos benéficos do lodo, este pode apresentar, também, uma série de metais pesados potencialmente tóxicos, tais como: zinco, cobre, níquel, chumbo, cádmio e mercúrio, entre outros. Alguns desses elementos são micronutrientes essenciais às plantas e animais e outros não têm nenhuma função biológica conhecida (Oliveira et al., 2003).

Nos solos contaminados por metais pesados os métodos de extração seqüencial têm sido usados para identificar as frações químicas nas quais esses elementos se encontram predominantemente associados (Tessier et al., 1979).

Tem se notado considerável interesse no desenvolvimento de estratégias de remediação in situ de solos contaminados com metais pesados, que sejam eficientes e duráveis (Mesquita, 2002; Pinheiro, 2003). Dentre as técnicas de remediação in situ está a estratégia de Imobilização Química, também denominada Contenção do Contaminante, que consiste em minimizar a migração de metais pesados para a subsuperfície do solo como, também, reduzir sua biodisponibilidade. As técnicas são baseadas na incorporação de agentes com potencial para complexação e/ou precipitação causando a imobilização química. Ao serem aplicados aos solos, esses produtos reduzirão a disponibilidade e mobilidade desses elementos, através do aumento da adsorção específica na superfície das partículas do solo e da precipitação química na solução do solo (Araújo et al., 2002). Desta forma, reduz a sua toxicidade, mas sem diminuir a concentração no solo. Adição de carbonatos (Jackson \& Alloway, 1992), óxidos (Brown et al., 1989), fosfatos (Pierzynski et al., 1998), e matéria orgânica (Oliveira et al., 2003; Pinheiro, 2003), com tal finalidade, tem sido descrita na literatura.

Este trabalho teve, como objetivos:

- Estudar as alterações provocadas pela aplicação de diferentes produtos nas diversas formas químicas de $\mathrm{Zn}$ no solo, em solos tratados com lodo de esgoto contaminado;

- Avaliar a eficiência de diferentes produtos na contenção de Zn em solos contaminados com esse elemento, pela aplicação de lodo de esgoto contaminado;

- Testar a estratégia de imobilização química usando planta hiperacumuladora.

\section{MATERIAL E MÉTODOS}

O experimento de laboratório foi conduzido nas instalações do Departamento de Solos da UFRRJ, utilizando-se os solos Latossolo Vermelho Amarelo (LV) e Argissolo Vermelho Amarelo (PV) tratados com lodo de esgoto do tratamento secundário, proveniente de indústria metalúrgica, com elevado teor de Zn. A coleta do lodo consistiu em retirar amostras simples do topo, meio e base da pilha de lodo, depositada no pátio de armazenamento da indústria, formando uma amostra composta (ABNT, 1987).

O lodo foi secado ao ar, destorroado, passado por peneira de malha de $2 \mathrm{~mm}$ e caracterizado quimicamente, Tabela 1.

As amostras de solo coletadas nos primeiros $20 \mathrm{~cm}$ de profundidade, foram secadas ao ar, destorroadas e passadas em peneira de malha de $2 \mathrm{~mm}$ para obtenção da terra fina secada ao ar (TFSA). A caracterização física e química desses solos, Tabela 2, foram feitas de acordo com o Manual de Métodos de Análise de Solos (EMBRAPA, 1997). Nas amostras de TFSA do LV e PV adicionou-se lodo em quantidade equivalente a $60 \mathrm{Mg} \mathrm{ha}^{-1}$ em base de matéria seca. Após a adição do lodo ao solo, as amostras foram homogeneizadas e acondicionadas em sacos plásticos, em umidade equivalente à capacidade de campo. A manutenção da umidade foi controlada através de pesagens periódicas e as amostras foram mantidas em laboratório, a temperatura ambiente, por um período de aproximadamente 36 meses, antes de sua utilização neste estudo.

Instalou-se, em laboratório, um experimento em vasos plásticos com $400 \mathrm{~g}$ dos solos LV e PV tratados com o lodo contaminado. O experimento constou de quatro tratamentos e seis repetições totalizando 48 unidades experimentais.

Para avaliar os efeitos de produtos imobilizadores de metais pesados, aplicaram-se os seguintes tratamentos:

$\mathrm{T}_{1}$ - Mistura solo-lodo (Testemunha)

$\mathrm{T}_{2}$ - Mistura solo-lodo + fosfato de potássio $\left(\mathrm{KH}_{2} \mathrm{PO}_{4}\right)$

$\mathrm{T}_{3}$ - Mistura solo-lodo + carbonato de cálcio $\left(\mathrm{CaCO}_{3}\right)$

$\mathrm{T}_{4}$ - Mistura solo-lodo $+50 \mathrm{~mL}$ de solução saturada de Cloreto férrico $\left(\mathrm{FeCl}_{3}\right)+$ EDTA na concentração de $0,07 \mathrm{~mol} \mathrm{~L}{ }^{-1}$.

A quantidade adicionada de $\mathrm{KH}_{2} \mathrm{PO}_{4}$ foi equivalente a $65,1 \mathrm{~kg} \mathrm{ha}^{-1}$ e a de $\mathrm{CaCO}_{3}$ foi baseada na curva de neutralização para atingir pH 6,5.

As misturas foram incubadas no laboratório durante 200 dias, em umidade equivalente à capacidade de campo, para estabilização do pH. Após este período, amostras foram retiradas para realização das extrações simples.

Os extratores utilizados, foram: água, nitrato de sódio, ácido acético e DTPA. A extração com água consistiu em agitar 5 g de solo, por uma hora, a temperatura ambiente, com $50 \mathrm{~mL}$ da solução de água deionizada. Na extração com nitrato de sódio $5 \mathrm{~g}$ de solo foram agitados, durante duas horas, a temperatura ambiente, com $50 \mathrm{~mL}$ da solução extratora de $\mathrm{NaNO}_{3}$ 
Tabela 1. Caracterização química e fracionamento da matéria orgânica do lodo de esgoto em estudo

\begin{tabular}{|c|c|c|c|c|c|c|c|c|c|c|c|c|c|}
\hline $\mathrm{pH}\left(\mathrm{H}_{2} \mathrm{O}\right)$ & $\mathrm{C}_{\text {org }}$ & $\mathrm{N}_{\text {total }}$ & $\mathrm{MO}^{1}$ & $\mathbf{P}$ & $\mathrm{K}$ & $\mathrm{Ca}$ & $\mathrm{Mg}$ & \multirow{2}{*}{$\mathrm{C} / \mathrm{N}$} & $\mathrm{Cu}$ & Cd & $\mathrm{Pb}$ & Mn & $\mathrm{Zn}$ \\
\hline$(1: 2,5)$ & & & & $\mathrm{g} \mathrm{kg}^{-1}$ & & & & & \multicolumn{5}{|c|}{$\mathrm{mg} \mathrm{kg}^{-1}$} \\
\hline 7,0 & 186 & 21,5 & 335 & 8,0 & 1,8 & 25 & 5 & 8,65 & 47 & 0,75 & 82 & 60 & 7880 \\
\hline \multicolumn{14}{|c|}{ Fracionamento da matéria orgânica ${ }^{2}$} \\
\hline \multicolumn{4}{|c|}{ Ácido húmico } & & Ivico & \multirow{2}{*}{\multicolumn{2}{|c|}{$\mathrm{AH} / \mathrm{AF}^{3}$}} & $\mathrm{Fe}_{\mathrm{dit}}{ }^{4}$ & $\mathrm{Fe}_{\mathrm{ox}}{ }^{5}$ & $\mathbf{A l}_{\text {dit. }}$ & $\mathbf{A l}_{\mathrm{ox}}$ & $S i_{\text {dit. }}$ & $S \mathbf{i}_{0 x}$ \\
\hline \multicolumn{6}{|c|}{$\mathrm{g} \mathrm{kg}^{-1}$ lodo } & & & \multicolumn{6}{|c|}{$\mathrm{mg} \mathrm{kg}^{-1}$} \\
\hline \multicolumn{4}{|c|}{0,96} & \multicolumn{2}{|c|}{4} & \multicolumn{2}{|c|}{0,24} & 653 & 464 & 127 & 132 & 23 & 15 \\
\hline
\end{tabular}

${ }^{1}$ Matéria Orgânica; ${ }^{2}$ Dados de Canellas et al. (1999); ${ }^{3}$ Relação AH/AF = indicativo do grau de estabilização da matéria orgânica; ${ }^{4}$ Extraído com ditionito de sódio; ${ }^{5}$ Extraído com oxalato de amônio

Tabela 2. Características físicas e químicas da camada arável dos solos em estudo

\begin{tabular}{|c|c|c|c|c|c|c|c|c|c|c|c|c|c|}
\hline & $\mathrm{pH}\left(\mathrm{H}_{2} \mathrm{O}\right)$ & $C_{\text {org. }}$ & $\mathrm{N}_{\text {Total }}$ & M01 & $\mathrm{C}$ & $\mathbf{P}^{2}$ & $\mathrm{Ca}$ & $\mathrm{Mg}$ & $K$ & $\mathrm{Al}$ & $\mathrm{Zn}$ & CTC $^{3}$ & V \\
\hline & $1: 2,5$ & & $\mathrm{~g} \mathrm{~kg}^{-1}$ & & $U / N$ & $\mathrm{mg} \mathrm{kg}^{-1}$ & \multicolumn{6}{|c|}{$\mathrm{cmol}_{\mathrm{c}} \mathrm{kg}^{-1}$} & $\%$ \\
\hline LV & 4,4 & 14,0 & 2,0 & 24,1 & 7,0 & 7 & 1,0 & 1,8 & 0,3 & 2,0 & 29,1 & 14,3 & 22 \\
\hline \multirow[t]{3}{*}{ PV } & 4,6 & 9,2 & 1,4 & 15,8 & 6,6 & 1 & 1,7 & 1,3 & 0,12 & 0,5 & 27,5 & 5,8 & 54 \\
\hline & $\mathrm{SiO}_{2}$ & $\mathrm{Al}_{2} \mathrm{O}_{3}$ & $\mathrm{Fe}_{2} \mathrm{O}_{3}$ & $\mathrm{TiO}_{2}$ & $\mathrm{Al}_{2} \mathrm{O}_{3} / \mathrm{Fe}_{2} \mathrm{O}_{3}$ & Argila & Areia & Silte & $\mathrm{Ki}$ & $\mathbf{K r}$ & $\begin{array}{l}\text { Classe } \\
\text { Textural }\end{array}$ & $\begin{array}{c}\text { Min } \\
\text { da fra }\end{array}$ & $\begin{array}{l}\text { gia } \\
\text { argila }\end{array}$ \\
\hline & \multicolumn{4}{|c|}{$\mathrm{g} \mathrm{kg}^{-1}$} & \multicolumn{4}{|c|}{$\mathrm{g} \mathrm{kg}^{-1}$} & & & & \multirow{2}{*}{\multicolumn{2}{|c|}{$\begin{array}{c}\text { Caulinita, Gibsita } \\
\text { e Goethita }\end{array}$}} \\
\hline LV & 186 & 155 & 100 & 2,88 & 2,43 & 550 & 350 & 100 & 2,04 & 0,50 & Argila & & \\
\hline PV & 174 & 137 & 77 & 1,88 & 2,79 & 430 & 470 & 100 & 2,15 & 0,55 & $\begin{array}{l}\text { Argilo } \\
\text { arenosa }\end{array}$ & \multicolumn{2}{|c|}{$\begin{array}{l}\text { Caulinita, Gibsita } \\
\text { e Goethita }\end{array}$} \\
\hline
\end{tabular}

${ }^{1}$ Matéria Orgânica; ${ }^{2}$ Extraído com HCl $0,05 \mathrm{~mol} \mathrm{~L}^{-1} \mathrm{e} \mathrm{H}_{2} \mathrm{SO}_{4} 0,025 \mathrm{~mol} \mathrm{~L}^{-1}$; ${ }^{3}$ Extraído com acetato de cálcio

1 mol L-1. Na extração com ácido acético agitaram-se 5 g de solo, pelo tempo de uma hora, a temperatura ambiente, com $50 \mathrm{~mL}$ de $\mathrm{CH}_{3} \mathrm{COOH} 0,043 \mathrm{~mol} \mathrm{~L}^{-1}$ (Ure et al., 1993). Na extração com DTPA preparou-se a solução dissolvendo-se $149,2 \mathrm{~mL}$ de TEA, 19,67 g de DTPA e $14,7 \mathrm{~g}$ de $\mathrm{CaCl}_{2} 2 \mathrm{H}_{2} \mathrm{O}$ em aproximadamente 2,0 L de água destilada. Aguardou-se o tempo suficiente para dissolução do DTPA e se o diluiu para aproximadamente $9 \mathrm{~L}$. Após ajustar o $\mathrm{pH}$ para 7,3 \pm 0,05 com $\mathrm{HCl}\left(6 \mathrm{~mol} \mathrm{~L}^{-1}\right)$ elevou-se o volume para $10 \mathrm{~L}$ com água destilada. A extração consistiu em se agitar, por duas horas, $5 \mathrm{~g}$ de solo com $50 \mathrm{~mL}$ da solução de DTPA. A análise para os teores totais foi feita por meio de digestão nitroperclórica (Lindsay \& Norvell, 1978).

Após filtragem com papel qualitativo, os extratos foram acidificados, colocando-se duas gotas de ácido nítrico, com a finalidade de evitar a proliferação de fungos; em seguida, foram armazenados na geladeira, para posterior determinação dos teores de Zn por espectrofotometria de absorção atômica.

Os teores das diferentes frações químicas de Zn dos solos tratados com lodo de esgoto contaminado, foram estimadas a partir das diferenças nas quantidades extraídas obtidas nas extrações simples. Obtiveram-se cinco frações, que serão definidas a seguir:

$\mathrm{F}_{1}-$ Extraído com água $\Rightarrow$ Fração solúvel em água.

$\mathrm{F}_{2}-$ Extraído com $\mathrm{NaNO}_{3}-$ Extraído com água $\Rightarrow$ Fração trocável, que compreende os metais ligados eletrostaticamente às partículas do solo.

$\mathrm{F}_{3}$ - Extraído com ácido acético - Extraído com $\mathrm{NaNO}_{3}$ $\Rightarrow$ Fração associada predominantemente a carbonatos e óxidos, formando complexos de transição com os grupamentos hidroxilas na superfície de óxidos amorfos do solo.

$\mathrm{F}_{4}$ - Extraído com DTPA - Extraído com ácido acético $\Rightarrow$ Fração predominantemente associada a óxidos de Fe, Mn e Al mais cristalinos e a compostos orgânicos mais estáveis, através da formação de complexos de esfera interna.

$\mathrm{F}_{5}$ - Total - Extraído com DTPA $\Rightarrow$ Fração associada a óxidos com alto grau de cristalinidade (fração residual).

Após 200 dias de incubação, as unidades experimentais foram utilizadas no experimento de laboratório para instalação de um experimento em casa de vegetação. Utilizou-se, como planta teste (dez plantas por vaso), o arroz (Oriza sativa L.), cultivar IAC 47. Todos os tratamentos receberam adubação básica na época do plantio, com os seguintes nutrientes em solução: $100 \mathrm{mg} \mathrm{kg}^{-1}$ de $\mathrm{N}$ e $100 \mathrm{mg} \mathrm{kg}^{-1}$ de $\mathrm{KH}_{2} \mathrm{PO}_{4}$. Após quarenta dias da germinação foram colhidas, separadamente, a parte aérea e as raízes que, posteriormente, foram secadas em estufa de circulação forçada de ar $\left(60^{\circ} \mathrm{C}\right)$ para determinação da massa da matéria seca. As amostras de plantas (parte aérea e raízes), foram submetidas a digestão nitroperclórica. Determinaram-se os teores de Zn nos extratos por espectrofotometria de absorção atômica. O delineamento experimental utilizado foi o de blocos ao acaso, com oito tratamentos e seis repetições, totalizando quarenta e oito unidades experimentais.

As análises estatísticas foram feitas utilizando-se o teste de Tukey a 5\% para comparar médias entre os teores de metais pesados no solo e nas plantas, utilizando-se o Programa Estatístico SAEG Versão 5.0 (Euclydes, 1994).

\section{RESULTADOS E DISCUSSÃO}

Os teores das diferentes frações químicas de $\mathrm{Zn}$, nos solos $\mathrm{LV}$ e PV, decorrentes da aplicação de: $\mathrm{CaCO}_{3}$, $\mathrm{KH}_{2} \mathrm{PO}_{4}$ e $\mathrm{FeCl}_{3}+$ EDTA, são apresentados na Figura 1. Quando se comparam os teores de zinco nas frações solúvel em água (F1) e trocável (F2), do tratamento com 
$\mathrm{CaCO}_{3}$ com a testemunha nas mesmas frações observa-se, no solo LV (Figura 1A) que a adição desse produto provocou decréscimo nas percentagens deste elemento nas duas frações. Quando se analisa a fração F3 (fração associada a carbonatos e óxidos), com a adição do $\mathrm{CaCO}_{3}$, parte do Zn, que estava nas frações solúvel em água (F1) e ligado eletrostaticamente às partículas do solo (F2), passou para formas químicas mais estáveis, como, carbonato de Zn e adsorvidos na superfície de óxidos amorfos pela formação de complexos de transição associadas à fração F3; esses resultados estão de acordo com os mencionados na literatura (Alloway, 1995; Kabata-Pendias, 1992; McBride, 1989; Amaral Sobrinho et al., 1998) na qual se constatou que a adição de carbonato de cálcio aos solos e o conseqüente aumento de $\mathrm{pH}$, ocasionaram a precipitação de metais na forma de carbonatos e favoreceu a adsorção específica nos grupamentos funcionais de superfície que têm cargas dependentes de $\mathrm{pH}$ (hidroxilas funcionais), decrescendo a disponibilidade e mobilidade da maioria desses metais.
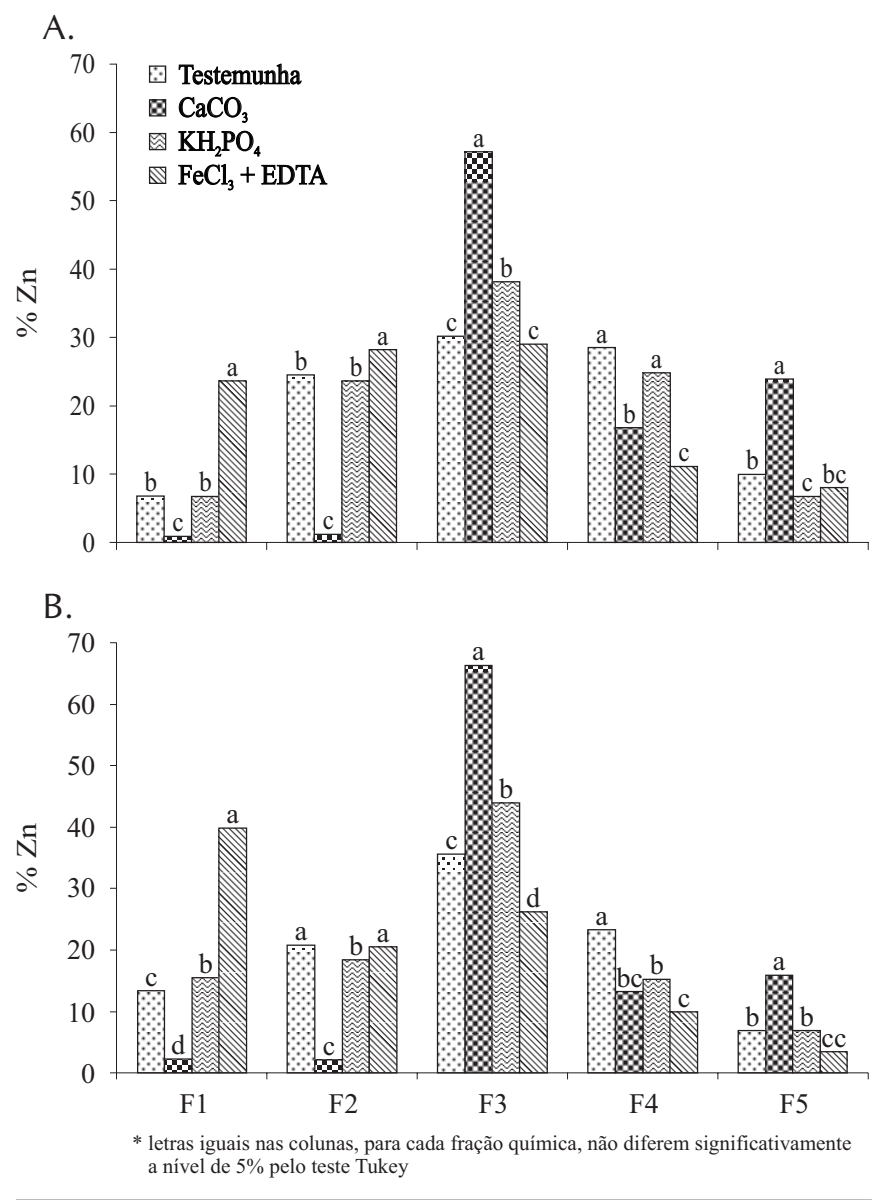

Figura 1. Percentagem do total de $\mathrm{Zn}$, nas diferentes formas químicas encontradas nos solos LV(A) e PV (B)

A adição de $\mathrm{CaCO}_{3}$ provocou redução significativa no teor de Zn associado à fração F4 (associados a óxidos de Fe e Mn) quando comparado com a testemunha; entretanto, verificase elevação significativa na F5 (fração residual). O decréscimo na F4 se deveu, provavelmente, à adsorção específica na superfície de óxidos de Fe com alto grau de cristalinidade e/ou oclusão associados à fração F5. Considerando-se a alta estabilidade da adsorção de Zn na fração F5 (formação de complexos internos e oclusão) pode-se inferir que a adição do $\mathrm{CaCO}_{3}$ levou a uma contenção eficiente ou imobilização química deste elemento no solo LV.

No tratamento com $\mathrm{CaCO}_{3}$, como ocorreu com o solo $\mathrm{LV}$, grande parte do $\mathrm{Zn}$ esteve associada à fração $\mathrm{F} 3$, dados que confirmam que a adição de $\mathrm{CaCO}_{3}$ favoreceu a transferência de Zn das frações solúvel em água (F1) e trocável (F2) para outras frações menos solúveis. Com relação às frações F4 e F5 observou-se que, de maneira geral, os teores de $\mathrm{Zn}$ foram menores no solo PV, quando comparado com o solo LV (Figura 1A). O comportamento distinto desses dois solos reflete a diferença relacionada ao poder tampão, como discutido anteriormente.

As percentagens de zinco nas diferentes formas químicas no PV, em decorrência da aplicação dos produtos, são apresentadas na Figura 1B. Quando se compararam os teores de zinco nas frações solúvel em água (F1B) e na trocável (F2) no tratamento com $\mathrm{CaCO}_{3}$ com a testemunha observou-se que, de forma semelhante ao ocorrido no solo LV, a adição de $\mathrm{CaCO}_{3}$ ao sistema provocou decréscimo significativo nos teores de $\mathrm{Zn}$ nessas frações. Analisando-se os dois solos verifica-se, no entanto, que a porcentagem de $\mathrm{Zn}$ na fração solúvel em água foi maior no solo PV (Figura 1) o que, provavelmente, se deveu ao menor poder tampão deste solo, decorrente do menor teor de argila e matéria orgânica, quando comparado com o solo LV, Tabela 2.

De modo geral, quando se compara o percentual de $\mathrm{Zn}$ no tratamento contendo fosfato de potássio e a testemunha, no solo LV (Figura 1A), observa-se que os teores de $\mathrm{Zn}$ nas frações solúvel em água (F1) e trocável (F2) não diferiram significativamente. Avaliando-se, em conjunto, as demais frações, encontra-se que a F3 aumentou e as frações F4 e F5 decresceram quando comparadas com a testemunha. O efeito não observado sobre as frações F1 e F2 pode ter sido causado pela alta capacidade de adsorção de fosfatos desse solo intemperizado reduzindo, desta forma, a concentração desse ânion na solução do solo para precipitar com o Zn. O aumento na fração F3 foi decorrente do aumento de cargas líquidas negativas na superfície dos óxidos amorfos, provocado pela adsorção de fosfato, que favoreceu a formação de complexos internos do $\mathrm{Zn}$ com as hidroxilas na superfície dos óxidos amorfos. O aumento de cargas líquidas negativas pela adição de fosfatos tem sido descrito na literatura (Sposito, 1989).

Analisando-se os efeitos da adição de $\mathrm{FeCl}_{3}+$ EDTA no solo LV, observou-se que, ao contrário do verificado com o tratamento $\mathrm{CaCO}_{3}$, as percentagens de Zn nas frações solúvel em água (F1) e trocável (F2) foram mais elevadas que no tratamento testemunha (Figura 1A). Nas frações F4 e F5, porem, os teores de $\mathrm{Zn}$ foram inferiores cujo resultado se deveu ao baixo valor de $\mathrm{pH}$, ao redor de 4,0, neste tratamento, Tabela 3, causando, sem dúvida, a dissolução dos compostos de Zn e a dessorção pelo EDTA de parte do Zn complexado por grupos funcionais de superfície, inibindo a capacidade adsortiva dos óxidos de ferro. 
Tabela 3. Valores médios de pH nos tratamentos nos solos estudados

\begin{tabular}{lcc}
\hline Tratamento & \multicolumn{2}{c}{ Solo } \\
\cline { 2 - 3 } Testemunha & PV1 & LV2 \\
$\mathrm{CaCO}_{3}$ & 4,53 & 4,69 \\
$\mathrm{KH}_{2} \mathrm{PO}_{4}$ & 6,39 & 5,94 \\
$\mathrm{FeCl}_{3}+$ EDTA & 4,56 & 4,76 \\
\hline
\end{tabular}

Com a aplicação de $\mathrm{FeCl}_{3}+$ EDTA observou-se, de modo geral, no solo PV, a mesma tendência do solo LV, aumento na F1 e redução significativa das frações F3, F4 e F5, quando comparado com o tratamento testemunha causada, provavelmente, pela dissolução dos óxidos, devido ao baixo $\mathrm{pH}$ (Figura 2B) e à dessorção provocada capacidade quelatante do EDTA, que deve ter contribuído para o deslocamento deste elemento na superfície dos óxidos de ferro e na matéria orgânica estável, permanecendo o Zn em solução complexado pelo EDTA. Esses resultados demonstram claramente que adição $\mathrm{FeCl}_{3}$ + EDTA determinou, em ambos os solos, efeito contrário ao esperado, aumento da labilidade do Zn.

A Figura 2 apresenta a produção de matéria seca total da parte aérea e raízes do arroz (IAC 47), cultivado nos solos LV e PV tratados com diferentes produtos. Quando se comparam os tratamentos testemunha, $\mathrm{CaCO}_{3}$ e fosfato, observa-se que não ocorreu diferença significativa na produção de matéria seca da parte aérea e raiz, mas para o solo LV o tratamento $\mathrm{FeCl}_{3}$ + EDTA ocorreu redução significativa da produção de matéria seca da parte aérea, quando comparado com a testemunha. A produção de matéria seca das raízes, nos dois solos, foi inferior aos outros tratamentos. Apesar do aumento do $\mathrm{pH}$ provocado pela adição do $\mathrm{CaCO}_{3}$, de 4,7 para 6,1 , no solo LV e 4,4 para 6,0, no solo PV, Tabela 3, reduzindo significativamente os teores de $\mathrm{Zn}$ nas frações de maior biodisponibilidade (F1 e F2), essas mudanças não foram suficientes para provocar aumento na produção de matéria seca total da planta. Resultados semelhantes foram observados por Oliveira et al. (2003) estudando o efeito da aplicação nos solos de até 80 t ha-1 de lodo de esgoto enriquecido com Zn na produção de matéria seca do arroz (IAC 47), nos solos LV e PV, contendo 569,1 e 506,9 $\mathrm{mg} \mathrm{kg}^{-1}$ de $\mathrm{Zn}$, respectivamente. Mecanismos de tolerância da planta de arroz ao alto teor de Zn foram, provavelmente estimulados. Essas evidências foram melhor elucidadas quando se verificou acúmulo deste material nas raízes, com o aumento da dose de lodo, indicando ser este órgão muito tolerante, contribuindo para reduzir os teores de metais nos outros órgãos da planta e, conseqüentemente, a toxicidade (Oliveira et al., 2005).

Com a adição do $\mathrm{FeCl}_{3}$ + EDTA, no entanto, ocorreu significativa redução na produção de matéria seca nos dois solos (Figura 2) resultados devidos à redução do $\mathrm{pH}$, Tabela 3, nos dois solos, provocando solubilização de compostos associados ao Zn e conseqüente disponibilidade deste (Figura 1), causando toxidez nas plantas de arroz e redução na produção de matéria seca.

As concentrações de Zn na parte aérea e raiz do arroz (IAC 147) cultivado nos solos LV e PV, sob condições de casa de vegetação, são apresentadas na Figura 3.
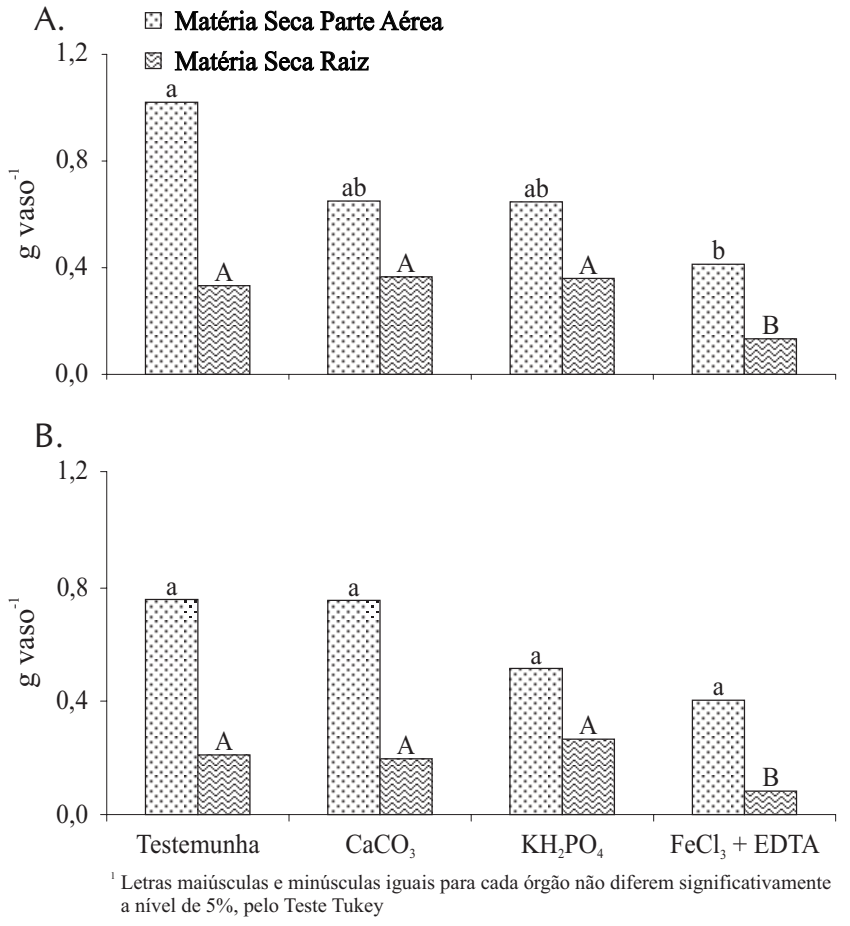

Figura 2. Produção de matéria seca da parte aérea e raízes das plantas de arroz (IAC-147) cultivadas nos solos LV (A) e PV (B)
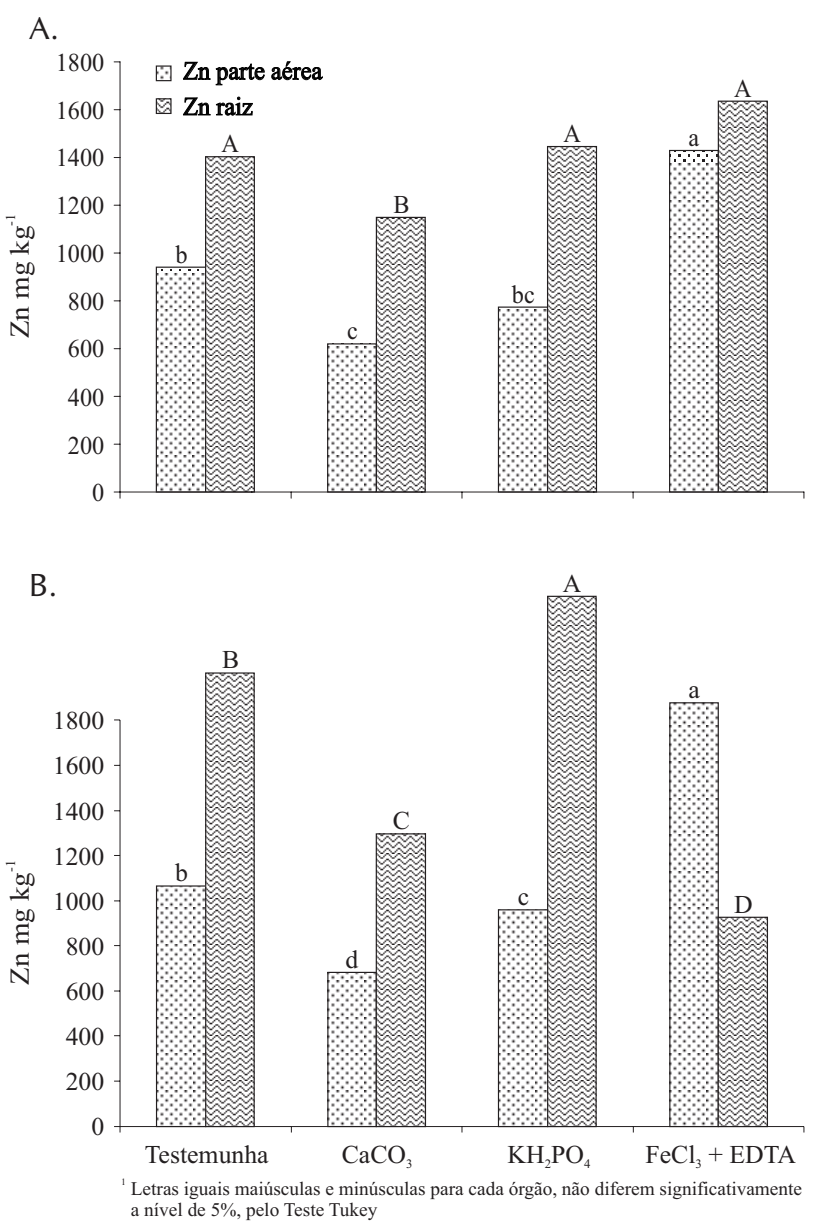

Figura 3. Teores de Zn na parte aérea e raízes de arroz (IAC-147), cultivado nos solos LV e PV, sob condições de casa de vegetação 
Analisando-se o solo LV observa-se que os teores de $\mathrm{Zn}$ nos tratamentos testemunha, $\mathrm{CaCO}_{3}$ e fosfato foram significativamente maiores na raiz quando comparados com a parte aérea. Nas raízes, os teores de Zn variaram de 1149 mg kg-1, no tratamento $\mathrm{CaCO}_{3}$ a $1630 \mathrm{mg} \mathrm{kg}^{-1}$ no tratamento $\mathrm{FeCl}_{3}$ + EDTA; nas folhas, os teores oscilaram de $619 \mathrm{mg} \mathrm{kg}^{-1}$ no tratamento $\mathrm{CaCO}_{3}$ a $1446 \mathrm{mg} \mathrm{kg}^{-1}$ no tratamento $\mathrm{FeCl}_{3}+$ EDTA. Os teores de $\mathrm{Zn}$ nesses tratamentos foram de 1,5 a 1,8 vez superior nas raízes que na parte aérea, indicando que as raízes atuaram como importante "filtro" deste elemento, evitando transferência para a parte aérea. Oliveira et al. (2005) estudando esses mesmos solos tratados com lodo de esgoto enriquecido com $\mathrm{Cd}, \mathrm{Pb}$ e $\mathrm{Zn}$, encontraram que referidos elementos se concentraram, fundamentalmente, nas raízes, com conseqüente redução na sua transferência para as folhas e grãos.

A acumulação de $Z n$ nas raízes pode ter sido desencadeada por um mecanismo de tolerância neste órgão como, por exemplo, a exudação de substâncias quelantes, através de ligação do metal às cargas existentes na parede celular (Wang \& Evangelou, 1994).

A nível de citoplasma da célula poderia ocorrer complexação do metal (Zn) com ácidos orgânicos (citrato) e inorgânicos $\left(\mathrm{H}_{2} \mathrm{~S}\right)$, fitatos e fitoquelatinas. Todos esses compostos formados foram armazenados, possivelmente, nos vacúolos, na forma menos tóxica para a planta (Wang \& Evangelou, 1994; Steffens, 1990).

Comparando-se os diferentes tratamentos, verifica-se que no tratamento $\mathrm{CaCO}_{3}$ os teores de $\mathrm{Zn}$ foram menores na raiz e na parte aérea. Esses resultados são coerentes com os obtidos no experimento em laboratório, quando se verificou que a aplicação deste corretivo ocasionou expressivo decréscimo deste elemento nas frações mais lábeis (solúvel em água e trocável), reduzindo a biodisponibilidade, absorção e transporte do elemento para a parte aérea.

Por outro lado, no tratamento $\mathrm{FeCl}_{3}+$ EDTA os teores de Zn na parte aérea foram mais elevados indicando, como observado em condições de laboratório, que a aplicação deste tratamento promoveu solubilização de $\mathrm{Zn}$ dos componentes orgânicos e inorgânicos, aumentando a disponibilidade, absorção e transporte deste elemento para a parte aérea.

Quando se analisam os teores de zinco na parte aérea e raiz da planta cultivada no solo PV, verifica-se que a acumulação deste elemento foi maior na raiz nos tratamento Testemunha, $\mathrm{CaCO}_{3}$ e $\mathrm{KH}_{2} \mathrm{PO}_{4}$ (Figura 3). Quando se avaliam os diferentes tratamentos verifica-se que, semelhante ao ocorrido com o solo $\mathrm{LV}$, no tratamento $\mathrm{CaCO}_{3}$ os teores de $\mathrm{Zn}$ nos órgãos analisados foram menores, cujo resultado, como discutido anteriormente, foi causado pelo decréscimo na disponibilidade deste elemento pelo aumento do $\mathrm{pH}$. No tratamento $\mathrm{FeCl}_{3}+$ EDTA, diferentemente do solo LV, os teores de Zn na parte aérea foram maiores que na raiz (ao redor de 2 vezes), mostrando grande transferência de zinco da raiz para a parte aérea. Esses resultados confirmam aqueles obtidos no experimento em laboratório (Figura 1B) quando se observou aumento no percentual de Zn na fração de maior disponibilidade (F1).

A Tabela 4 apresenta os coeficientes de correlação linear simples entre as concentrações de Zn nas diferentes frações químicas dos solos LV e PV e as concentrações deste elemento na parte aérea e raiz e com a produção de matéria seca (parte aérea e raiz). Observa-se que, nos solos LV e PV, ocorreram correlações positivas e altamente significativas entre a fração F1 (solúvel em água), e a concentração de Zn na parte aérea e raiz. Com a fração F2 (extraível com $\mathrm{NaNO}_{3}$ ), as correlações também foram positivas e altamente significativas, porém de menor magnitude. As correlações entre a fração F5 (de menor disponibilidade) e as concentração de Zn, ao contrário do verificado com as frações F1 e F2, foram negativas e significativas, em sua maioria. Esses resultados confirmam a maior biodisponibilidade dos metais na fração F1 e em menor intensidade a fração F2 e a indisponibilidade para plantas da fração F5.

Os coeficientes de correlação entre as frações F1 e F2 e a concentração de Zn na parte aérea e concentração de Zn na raiz, Tabela 4, foram, de maneira geral, positivas e significativos. Os coeficientes de correlação entre a fração F5 concentração de Zn na parte aérea e concentração de Zn na raiz, foram negativos e significativos. A interpretação das correlações confirma os resultados obtidos em laboratório e casa de vegetação, mostrando que as frações químicas de maior biodisponibilidade (F1 e F2) ou a de menor disponibilidade (F5) podem ser úteis para predizer a absorção de zinco pelas plantas indicadoras.

Tabela 4. Coeficientes de correlação linear simples entre as diferentes frações químicas de Zn dos solos LV e PV e as concentrações de Zn na parte aérea, raiz e matéria seca total nas amostras tratadas com diferentes produtos

\begin{tabular}{|c|c|c|c|c|c|}
\hline \multirow{2}{*}{$\begin{array}{l}\text { Frações } \\
\text { Químicas }\end{array}$} & \multicolumn{5}{|c|}{ LV } \\
\hline & {$[\mathrm{PA}]^{(1)}$} & {$[\mathbf{R}]^{(2)}$} & MSPA(3) & $\mathrm{MSR}^{(4)}$ & MSTO(5) \\
\hline $\mathrm{F} 1$ & $0,922^{\star *}$ & $0,632^{\star *}$ & $-0,402 \mathrm{~ns}$ & $-0,867$ ** & $-0,600$ ** \\
\hline F2 & $0,746^{* *}$ & $0,624^{* *}$ & $-0,151 \mathrm{~ns}$ & $-0,552^{* *}$ & $-0,292 \mathrm{~ns}$ \\
\hline \multirow[t]{2}{*}{ F5 } & $-0,528^{* *}$ & $-0,638^{* *}$ & $0,188 \mathrm{~ns}$ & 0,295 ns & 0,074 ns \\
\hline & \multicolumn{5}{|c|}{ PV } \\
\hline $\mathrm{F} 1$ & $0,985^{\star *}$ & $0,511^{*}$ & $-0,457^{*}$ & $-0,692^{\star *}$ & $-0,567 * *$ \\
\hline F2 & $0,737^{* *}$ & $0,087 \mathrm{~ns}$ & $-0,386$ ns & $-0,277 \mathrm{~ns}$ & $-0,398 \mathrm{~ns}$ \\
\hline F5 & $-0,459^{*}$ & $-0,002$ ns & $0,187 \mathrm{~ns}$ & $0,065 \mathrm{~ns}$ & $0,175 \mathrm{~ns}$ \\
\hline
\end{tabular}

$\mathrm{F}_{1}$ (Fração solúvel em água); $\mathrm{F}_{2}$ (Fração trocável); $\mathrm{F}_{3}$ (Fração associada predominantemente a carbonatos $\mathrm{e}$

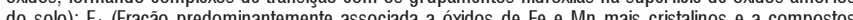
do solo), $\mathrm{F}_{4}$ (Fraçăo predominantemente associada a oxidos de $\mathrm{Fe}$ e $\mathrm{Mn}$ mais cristalinos e a compostos organnicos mais estaveis, atraves da formação de complexos de esfera interna); $F_{5}$ (fração residual). ${ }^{1}$ Concentração de Zn na parte aérea; ${ }^{2}$ Concentração de Zn na raiz; ${ }^{3}$ Matéria seca da parte aérea; ${ }^{4}$ Matéria

\section{CONCLUSÕES}

1. Nos solos LV e PV a adição de $\mathrm{CaCO}_{3}$ provocou imobilização química do Zn por sua associação às frações químicas mais estáveis. $\mathrm{O} \mathrm{FeCl}_{3}+$ EDTA, no entanto, causou decréscimo no $\mathrm{pH}$ do solo e dissolução de compostos de $\mathrm{Zn}$. $\mathrm{O} \mathrm{KH}_{2} \mathrm{PO}_{4}$ não alterou a distribuição de $\mathrm{Zn}$ nas diferentes formas químicas.

2. A produção de matéria seca da parte aérea, raiz e total, não foi afetada pela aplicação $\mathrm{CaCO}_{3}$ e $\mathrm{KH}_{2} \mathrm{PO}_{4}$. A adição de $\mathrm{FeCl}_{3}$ + EDTA afetou, de forma significativa, este parâmetro.

3. A adição de $\mathrm{CaCO}_{3}$ diminuiu a concentração de $\mathrm{Zn}$ na raiz e parte aérea. A adição de $\mathrm{FeCl}_{3}+\mathrm{EDTA}$, no entanto, elevou as concentrações de Zn nesses órgãos da planta.

4. O Zn se concentrou nas raízes, limitando a passagem desses elementos para a parte aérea. 


\section{LITERATURA CITADA}

ABNT - Associação Brasileira de Normas Técnicas. Amostragem de resíduos sólidos. NBR-10007. Rio de Janeiro: ABNT, 1987. 25p.

Alloway, B. J. Heavy metals in soils. London: Blackie A \& P, 1995. 368p.

Amaral Sobrinho, N. M. B.; Velloso, A. C. X.; Costa, L. M.; Oliveira, C. Mobilidade de metais pesados em solos tratados com resíduos siderúrgicos ácidos. Revista Brasileira de Ciência do Solo, Viçosa, v.22, p.345-353, n.2, 1998.

Andreoli, C. V.; Pegorini, E. S. Plano de reciclagem agrícola de lodo de esgoto do município de Maringá. Curitiba Sanepar, 1999. 100p.

Araújo, W. S.; Amaral Sobrinho, N. M. B.; Mazur, N.; Gomes, P. C. Relação entre adsorção de metais pesados e atributos químicos e físicos de classes de solo do Brasil. Revista Brasileira de Ciência do Solo, Viçosa, v.26, n.2, p.17-27, 2002.

Brown, P. H.; Dunemann, L.; Schulz, R.; Marschner, H. Influence of redox potential and plant species on the uptake of nickel and cadmium from soils. Soils and Fertilisers OS 052-08019. Z. Pflanzenernahr. Bodenkd., v.151, p.85-91. 1989.

Canellas, L. P.; Santos, G. A.; Amaral Sobrinho, N. M. B.; Moraes, A. A.; Rumjamek, V. M. Adsorção de Cu e Cd em ácidos húmicos extraídos de resíduos orgânicos de origem urbana. Revista Ciência Rural, Santa Maria, v.29, p.21-26, 1999.

EMBRAPA - Empresa Brasileira de Pesquisa Agropecuária. Centro Nacional de Pesquisa de Solos. Manual de métodos de análise de solos. 2.ed. Rio de Janeiro: (EDITORA) 1997. 212p.

Euclydes, R. F. Sistema de análises estatísticas e genéticas. Viçosa: CPD/UFV, Divisão de Pesquisa e Desenvolvimento, 1994. 59p.

Kabata-Pendias, A.; Pendias, H. Trace elements in soils and plants. Boca Raton: CRC, 1992. 315p

Jackson, A. P.; Alloway, B. J. Transfer of cadmium from soils to the human food chain, in Adriano, D.C., Biogeochemistry of Trace Metals, Boca Raton, Lewis Publisher, 1992. p.109-158.A.;

Lindsay, W. L.; Norwell, W. A. Development of a DTPA test zinc, iron, manganese and copper. Soil Science Society of America Proceeding, Madison, v.42, p.421-428, 1978.
McBride, M. B. Reactions controlling heavy metal solubility in soils. Advances in Soil Science, New York, v.10, p. 1-56. 1989.

Mesquita, A. A. Remediação de áreas contaminadas por metais pesados provenientes de lodo de esgoto. Seropédica: UFRRJ, 2002. 52p. Dissertação Mestrado

Oliveira, C.; Amaral Sobrinho, N. M. B.; Mazur, N. Evaluación del potencial de contaminación de barro cloacal enriquecido con cadmio y cinc en dos suelos agrícolas. Revista Terra, México, v.21, n.3, p.351-363, 2003.

Oliveira, C.; Amaral Sobrinho, N. M. B.; Santos, V. M.; Mazur, N. Efeitos da aplicação do lodo de esgoto enriquecido com cádmio e zinco na cultura do arroz. Revista Brasileira de Ciência do Solo. Viçosa, v.29, n.1 p.109-116, 2005.

Pierzynski, G. M.; Hettiarachchi, G. M.; Lambert, M. L.; Erickson, L. E.; Sweeney, D. W.; Hetrick, B. A. D. Remediation of metal-contaminated sites in tri-State mining region, USA. In: World Congress of Soil science, 16th, Workshop, 38, 1998, Montpellier, 1998. Cd Room.

Pinheiro, R. S. Inertização de resíduos perigosos através do uso de resíduos alcalinos. Seropédica: UFRRJ, 2003. 57p. Dissertação Mestrado

Sposito, G. The chemistry of soils. New York: Oxford University Press, 1989. 234p.

Steffens, J. C. The heavy metal-binding peptides of plants. Annual Review Plant Physiology and Plant Molecular Biology, Stanford, v.41, p.553-75, 1990.

Tessier, A.; Campbell, P. G. C.; Bisson, M. Sequential extraction procedure for the speciation of the particulate trace metals. Analytical Chemistry, Washington, v.51, p.844-851, 1979.

Ure, A.; Quevauviller, P. H.; Muntau, H.; Griepink, B. Speciation of heavy metals in soils and sediments, an account of the improvement and harmonization extraction techniques undertaken under the auspices of the BCR of the Commission of the European Communities International Journal of Environmental Analytical Chemistry, Philadelphia, v.51, p.135-151, 1993.

Wang, J.; Evangelou, V. P. Metal tolerance aspects of plant cell wall and vacuole-handbook of plant and crop physiology. Tucson:The University of Arizona, 1994. 325p. 